\title{
Auditory and audiovisual inhibition of return
}

\author{
CHARLES SPENCE \\ University of Oxford, Oxford, England \\ and \\ JON DRIVER \\ University College London, London, England
}

\begin{abstract}
Two experiments examined any inhibition-of-return (IOR) effects from auditory cues and from preceding auditory targets upon reaction times (RTs) for detecting subsequent auditory targets. Auditory RT was delayed if the preceding auditory cue was on the same side as the target, but was unaffected by the location of the auditory target from the preceding trial, suggesting that response inhibition for the cue may have produced its effects. By contrast, visual detection RT was inhibited by the ipsilateral presentation of a visual target on the preceding trial. In a third experiment, targets could be unpredictably auditory or visual, and no peripheral cues intervened. Both auditory and visual detection RTs were now delayed following an ipsilateral versus contralateral target in either modality on the preceding trial, even when eye position was monitored to ensure central fixation throughout. These data suggest that auditory target-target IOR arises only when target modality is unpredictable. They also provide the first unequivocal evidence for cross-modal IOR, since, unlike other recent studies (e.g., Reuter-Lorenz, Jha, \& Rosenquist, 1996; Tassinari \& Berlucchi, 1995; Tassinari \& Campara, 1996), the present cross-modal effects cannot be explained in terms of response inhibition for the cue. The results are discussed in relation to neurophysiological studies and audiovisual links in saccade programming.
\end{abstract}

The occurrence of a spatially uninformative peripheral visual cue often has a biphasic effect on detection latencies to subsequently presented visual targets (see, e.g., Posner \& Cohen, 1984). If the target is presented at a short interval (around 100-200 msec) after the onset of the cue, participants usually respond more rapidly to targets presented from the ipsilateral rather than the contralateral hemifield to the cue (although see Tassinari, Aglioti, Chelazzi, Peru, \& Berlucchi, 1994). Such outcomes have been attributed to a beneficial shift of exogenous covert attention toward the cued position (Posner, 1978), resulting in the superior processing of events at that location shortly after the cue (e.g., Bonnel, Possamaï, \& Schmitt, 1987). For present purposes, the more important result arises when the stimulus onset asynchrony (SOA) between cue and subsequent target extends beyond $200-300 \mathrm{msec}$. At such longer SOAs, the cuing effect usually reverses, so that participants now detect visual targets that are ipsilateral to the preceding cue more slowly than they detect contralateral ones (Maylor, 1985; Maylor \& Hockey, 1985; Posner \& Cohen, 1984). This effect, known as "inhibition of return" (IOR), lasts

This research was supported by grants from the Medical Research Council (U.K.) and Wellcome Trust, plus a Junior Research Fellowship to C.S. from St. John's College, Cambridge. We thank Neill Macmillan, Tram Neill, Giancarlo Tassinari, and Richard Wright for their helpful comments on an earlier draft of this article. Correspondence should be addressed to C. Spence, Department of Experimental Psychology, University of Oxford, South Parks Road, Oxford, OX1 3UD, England, or J. Driver, Institute of Cognitive Neuroscience, Department of Psychology, University College London, Gower Street, London, WC1E 6BT, England (e-mail: charles.spence@psy.ox.ac.uk or j.driver@psyc.bbk.ac.uk). for several seconds after cue onset (Tassinari \& Berlucchi, 1995) and is typically found in the absence of eye movements toward either the cue or the target location (Reuter-Lorenz et al., 1996). Posner and Cohen (1984, p. 541 and p. 549) originally proposed that the effect arises because covert attention is first drawn to the cued location but then moves on with an inhibitory bias against returning to the briefly attended cued location; hence the term inhibition of return.

Tassinari and colleagues have proposed instead that visual IOR is caused by an oculomotor suppression of the natural tendency to make a saccadic response toward the peripheral cue event (Berlucchi, Tassinari, Marzi, \& Di Stefano, 1989; Tassinari, Aglioti, Chelazzi, Marzi, \& Berlucchi, 1987; Tassinari, Biscaldi, Marzi, \& Berlucchi, 1989), as required by the usual central fixation instructions. They have suggested that the peripheral presentation of a visual cue automatically results in the generation of an orienting reflex to move the eyes in its direction. Participants must then prevent such an overt movement by generating a motor instruction against reacting to stimuli in the cued direction. Subsequent targets appearing on the side ipsilateral to the cue are then responded to more slowly, on this account, because the motor set that prevents saccades to the cue also impairs simple manual responses for events in that direction.

Several findings imply that there may indeed be strong links between visual IOR and the oculomotor system (Rafal, Calabresi, Brennan, \& Sciolto, 1989; Tassinari et al., 1987; Tassinari et al., 1989), but not all these results support the exact relationship envisaged by a strict oculomotor suppression account. IOR can affect both the 
latency of saccades (Abrams \& Dobkin, 1994a, 1994b; Vaughan, 1984) and their direction (Posner, Rafal, Choate, \& Vaughan, 1985). Maylor (1985) found that introducing an oculomotor secondary task (tracking a spot with unpredictable movements) abolished any IOR in response to a peripheral visual cue. By contrast, IOR was unaffected when the secondary task involved smoothpursuit eye tracking, rather than saccadic tracking (see also Wright \& Richard, in press, for further data on the secondary tasks that may disrupt visual IOR). Rafal et al. (1989) showed that endogenous saccade preparation results in IOR even when no saccade is subsequently executed, but reported that by contrast the endogenous orienting of covert attention alone apparently does not produce IOR.

Thus, several clear links between visual IOR and saccade programming have now been established. However, some of these do not seem to fit naturally with Tassinari and Berlucchi's oculomotor suppression hypothesis. For instance, Rafal, Egly, and Rhodes (1994) found that saccades in response to a peripheral target were slower when it appeared ipsilateral to a preceding uninformative cue, regardless of whether these saccades were toward or away from the target (countersaccades). One might have expected countersaccades to be faster for targets on the cued side rather than slower if a general set for any responses in the direction of the cue had been inhibited; responses in this direction were required for targets on the uncued side in the countersaccade condition. Rafal et al. also found that the IOR effect on saccades arose regardless of whether participants were required to maintain central fixation during the peripheral cue event or were required instead to orient their eyes to the cue and then return their gaze to fixation prior to target onset (i.e., under conditions where no oculomotor suppression was required). Posner et al. (1985) similarly found IOR when no saccade inhibition was required for the cue. Their participants made a saccade in the direction indicated by a central arrow in order to identify a digit presented at a peripheral location. Participants then had to refixate the center, prior to target onset. Detection latencies were slower for targets appearing at the location to which a peripheral saccade had just been made. Again, no saccadic suppression for the cue is necessary in this situation, and yet IOR was observed.

These results do not seem to be directly predicted by a strict saccadic suppression account. However, it remains possible that the saccadic suppression hypothesis holds for a subset of IOR effects. Moreover, the possible role of saccades back to central fixation, in generating any lateralized effects, should be considered for those studies that required eye movements out to the peripheral cue and then back again (e.g., Posner et al., 1985; Rafal et al., 1994; see Chelazzi et al., 1995, for one account of how IOR in such cases might be reconciled with the oculomotor suppression hypothesis).

The findings that IOR can occur even when saccades are actually executed to the cued location led Rafal and his colleagues (Rafal et al., 1989; Rafal \& Henik, 1994) to propose an alternative account for IOR in terms of oculomotor priming. They suggested that it is the preparation of an eye movement itself that is both necessary and sufficient for the subsequent generation of IOR in the direction of the prepared saccade. This account is consistent with Rafal et al.'s (1989) finding that endogenous saccade preparation produces IOR for the prepared side, even when the planned saccade is subsequently not executed.

Both the oculomotor suppression account for IOR (Berlucchi et al., 1989; Tassinari et al., 1987; Tassinari et al., 1989) and the oculomotor priming account (Rafal et al., 1989; Rafal \& Henik, 1994) predict that IOR should occur after any stimulus that normally elicits a saccade program, regardless of its modality. Although the majority of IOR research has focused on the inhibitory effects of a visual cue on responding to ipsilaterally presented visual target events (see Klein \& Taylor, 1994; Rafal \& Henik, 1994, for reviews), unexpected sounds are also known to lead to programming of eye movements (and other aspects of overt orienting such as head turns), and so might be expected to induce IOR. Overt orienting to sounds typically involves coordinated movement of the observer's eyes, head, and body in the direction of the auditory stimulus (see, e.g., Pumphrey, 1950; Sokolov, 1963; Thompson \& Masterton, 1978; Whittington, Hepp-Reymond, \& Flood, 1981). Moreover, it has been argued that saccades to sudden sounds are programmed automatically, in a similar fashion as for sudden visual events (Jay \& Sparks, 1990). Saccades to auditory events can certainly be executed very rapidly indeed (see, e.g., Fuller, 1992; Whittington et al., 1981).

Given such findings, the oculomotor priming account (Rafal et al., 1989; Rafal \& Henik, 1994) predicts that IOR should be found following auditory cues as well as after visual cues. The oculomotor suppression hypothesis (Berlucchi et al., 1989; Tassinari et al., 1987; Tassinari et al., 1989) makes the same prediction for situations in which saccades toward the auditory cues have to be suppressed. However, several cross-modal studies in both normals (Klein, Brennan, \& Gilani, 1987; Spence \& Driver, 1997a) and in unilateral parietal-lesioned patients (Farah, Wong, Monheit, \& Morrow, 1989) have failed to observe any IOR from uninformative auditory cues upon visual targets (see also Reuter-Lorenz \& Rosenquist, 1996). Participants in these experiments were presented on each trial with a spatially uninformative peripheral auditory cue on one side prior to a visual target on the same or opposite side, which either required a simple detection response (Farah et al., 1989; Klein et al., 1987) or an up/down spatial discrimination response (Spence \& Driver, 1997a). All studies reported an advantage in performance for visual targets on the side of the auditory cue at short cue-target SOAs, suggesting cross-modal covert orienting. However, no evidence for cross-modal IOR was reported at longer SOAs. Similarly, these studies yielded no evidence for cross- 
modal IOR in the reverse direction either, from a visual cue to a subsequent auditory target. Both Klein et al. (1987, Experiment 6) and Spence and Driver (1997a, Experiments 3-6) presented auditory targets after spatially uninformative visual cues and found no inhibitory effects on the cued side at longer cue-target intervals (or any facilitatory effects on that side at shorter intervals, in this particular cross-modal case).

There are several reasons why these previous studies may have failed to demonstrate cross-modal IOR effects. First, none of them presented a central reorienting event between the onset of the lateralized cue and that of the subsequent lateralized target. In the unimodal visual literature, several researchers have reported that IOR is more readily apparent when another event intervenes between cue and target. Typically, this intervening event is presented at central fixation (Posner \& Cohen, 1984; Terry, Valdes, \& Neill, 1994; but see Maylor, 1983, cited in Maylor, 1985, and Wright \& Richard, 1993, 1994, for exceptions). It has been argued that central cues direct participants' attention back to fixation from the cued location, prior to target onset. If this is not implemented, any persistent facilitatory effects caused by exogenous covert orienting to the cue may oppose inhibitory influences as they start to emerge, and so mask the IOR.

Second, the use of a limited range of cue-target SOAs in previous cross-modal studies means that any IOR effects emerging only at very long SOAs would have gone undetected. (The maximum cue-target SOA was $500 \mathrm{msec}$ in the Klein et al., 1987, study; $700 \mathrm{msec}$ in Spence \& Driver, 1997a; and 1,000 msec in Farah et al., 1989. Note that Farah et al.'s neuropsychological study revealed persistent visual facilitation on the auditorily cued side even at the 1,000-msec SOA, suggesting that the facilitatory effects of orienting to auditory events, which may mask any IOR, can be quite durable; see also Ward, 1994, on this point.)

Third, the particular auditory discrimination task (up vs. down) used by Spence and Driver (1997a) may be insensitive to IOR, since previous visual research has revealed that IOR affects response latencies only in certain discrimination tasks (e.g., Cheal, Chastain, \& Lyon, in press; Pratt, 1995), but not in others (e.g., Pontefract \& Klein, 1988, cited in Klein \& Taylor, 1994; Terry et al., 1994). It may be that the auditory elevation discrimination task used by Spence and Driver falls into the latter category. If so, their repeatedly null cuing effects at longer cue-target SOAs should not be taken as definitive evidence against the possible existence of auditory or cross-modal IOR.

A role for these various factors in obscuring crossmodal IOR might explain why Reuter-Lorenz et al. (1996) recently did observe inhibitory effects between visual cues and subsequent auditory targets at longer SOAs. They required either a simple detection response or a saccade to the auditory target; as noted earlier, both are known to be sensitive measures of IOR in unimodal visual studies. Their tasks also involved a central event between lateralized cue and subsequent target to draw attention back to the center; in addition, long SOAs $(1,000$ and $1,300 \mathrm{msec}$ ) were examined. Thus, this study addressed all three of the factors discussed earlier that might have made previous studies insensitive to any cross-modal IOR, and a positive result was reported.

Moreover, Tassinari and Berlucchi (1995) recently reported preliminary results that appear to provide evidence for IOR within audition. A spatially uninformative tone cue was presented from one of two loudspeakers placed on either side of the participant's head. After a variable SOA $(200,600,1,500$, or $4,000 \mathrm{msec})$, an identical target tone was presented from the ipsilateral or the contralateral side. Detection was slower for ipsilateral than contralateral auditory targets. However, this inhibitory effect was smaller than that typically seen in unimodal visual studies and reached significance only at the 600-msec SOA. Finally, Tassinari and Campara (1996) have also reported that there may be cross-modal links in IOR between the visual and tactile modalities.

Tassinari and Berlucchi (1995) and Reuter-Lorenz et al. (1996) have both attributed their inhibitory effects of ipsilateral cues on subsequent auditory detection latencies to true IOR. However, neither study ruled out an alternative explanation for the ipsilateral disadvantage that was observed in terms of manual response inhibition to the cue. It has been widely reported that participants exhibit a strong tendency to react manually toward the apparent source of both auditory and visual events (for reviews, see Simon, 1990; Simon, Craft, \& Webster, 1971). It has also been claimed that participants must actively inhibit motor programs such as pressing the response key for inappropriate nontarget events (e.g., precues) in order to prevent anticipatory responding (see De Jong, Liang, \& Lauber, 1994; Harvey, 1980). Any such inhibition of manual responses to the cue might lead to delayed manual responses for subsequent target events when in the same direction. This would produce an IORlike pattern of results in a rather similar manner to that envisaged by the oculomotor suppression account (Berlucchi et al., 1989; Tassinari et al., 1987; Tassinari et al., 1989), but now due to manual suppression.

On both these accounts, participants must inhibit any tendency to respond in the direction of the cue during the standard cuing task (which requires both that central fixation be maintained and that manual responses be withheld to cues that might otherwise trigger them). The difference between these two accounts for IOR-like results is only that one emphasizes inhibition of manual responses for events presented in the direction of the cue, while the oculomotor suppression account specifically emphasizes inhibition of saccades in the same direction (which is then thought to generalize to manual responses as well). Thus, the basic logic of these two accounts is very similar, but they differ in terms of which aspect of the motor system is presumed to be initially affected by inhibition in order to cause the spatially specific delay in responding. 
As noted earlier, response inhibition for cues may be involved in generating some, if perhaps not all, IOR-like effects. Manual response inhibition in particular should be triggered by any cue stimulus for which manual responses must be withheld, but note that it should not be triggered by preceding target stimuli, for which manual responses are executed rather than withheld. Thus, apparent IOR that is due to manual suppression should not be produced by a preceding target. By contrast, the various other accounts of IOR predict that it should be found after previous target events as well as after preceding cues. For instance, according to the oculomotor priming account (Rafal et al., 1989), IOR should occur after both cue and target stimuli because both should automatically generate a saccadic program to move the eyes in their direction. Similarly, according to the oculomotor suppression hypothesis, both targets and cues should generate IOR provided that saccades toward them must be prevented.

Such arguments have led several previous authors to distinguish between IOR-like results that are merely due to manual response inhibition and "true" IOR by examining any inhibitory effects arising when targets for successive trials appear on the same versus opposite sides. Several researchers have reported that a visual target can produce IOR for a subsequent visual target when appearing on the same rather than the opposite side (e.g., Maylor \& Hockey, 1985; Posner, Cohen, Choate, Hockey, \& Maylor, 1984; Tassinari et al., 1989; Terry et al., 1994). However, neither Reuter-Lorenz et al. (1996) nor Tassinari and Berlucchi (1995) addressed this issue for their visual-to-auditory and auditory-to-auditory effects, and so it remains unclear whether their inhibitory results merely reflect manual response inhibition for the preceding cue, "true" IOR, or some unknown combination of the two effects.

To summarize, numerous experiments have shown that the presentation of a spatially uninformative visual cue can have a delaying effect on detection RTs for ipsilaterally presented visual targets emerging at longer cue-target SOAs. At present, the most parsimonious explanation for many of these IOR results seems to be in terms of the inhibitory aftereffects of oculomotor priming (Rafal et al., 1989; Rafal et al., 1994), although other factors (e.g., oculomotor suppression or manual response inhibition) may be responsible for some of the inhibitory effects reported. Since sudden auditory events typically result in the generation of a saccadic response, as for visual events, sounds would also be expected to generate IOR on the oculomotor priming hypothesis and on the oculomotor suppression hypothesis. However, the relatively few studies of auditory and audiovisual IOR have either reported null results (Farah et al., 1989; Klein et al., 1987; Spence \& Driver, 1997a) or inhibitory effects between ipsilateral cues and subsequent targets (ReuterLorenz et al., 1996; Tassinari \& Berlucchi, 1995) that might conceivably be explained entirely in terms of man- ual response inhibition for the cue. No study to date has examined any auditory or audiovisual IOR effects between successive target events, for which manual response inhibition accounts would be ruled out. In the experiments reported here, we sought to examine all possible audiovisual links in IOR, both between spatially uninformative cues and subsequent targets and between successive targets.

\section{EXPERIMENTS 1A-1B}

Our first study was a further investigation of the preliminary observations reported in Tassinari and Berlucchi's (1995) article concerning possible inhibitory effects from a spatially uninformative auditory event on detection latencies to subsequent ipsilaterally presented auditory targets. We sought to replicate their auditory cue-target effect while also analyzing the data for any intertrial inhibitory effects between successive targets, in order to test manual response inhibition accounts. As argued above, unlike cue-target IOR effects, target-target effects cannot be explained by manual inhibition. We conducted two related experiments that, for ease of exposition, are presented here together as Experiments 1A and 1B. Experiment $1 B$ was a modification of Experiment $1 \mathrm{~A}$ that we introduced to make the comparison of cue-target and target- target effects as close as possible (i.e., by matching the nature and intensity of cue and target stimuli and matching some cue-target SOAs with some target-target SOAs).

\section{Method}

Participants. Eighteen participants ( 10 men and 8 women) were recruited by advertisement to take part in this experiment. The mean age for participants was 22 years, with a range of $16-27$ years, and all except 1 were right-handed. The participants in this and all subsequent experiments in this paper reported normal hearing and normal or corrected-to-normal vision and were naive as to the purpose of the experiments. Nine participants took part in Experiment $1 \mathrm{~A}$ and 10 took part in Experiment $1 \mathrm{~B}$ (i.e., 1 person participated in both $1 \mathrm{~A}$ and $\mathrm{BB}$ ).

Apparatus and Materials. All the studies were conducted in a darkened sound-proof booth $(178 \times 122 \times 91 \mathrm{~cm})$. Participants were seated at a table, facing straight ahead, with their heads resting on a chinrest. A yellow light-emitting diode (LED) was placed $49 \mathrm{~cm}$ in front of participants at eye level to serve as a fixation point. Four box-mounted oval loudspeaker cones $(12.7 \times 7.6 \mathrm{~cm}$, RS 245-304) were used to present the cue and target sounds. The loudspeakers were placed at the corners of an imaginary rectangle centered on the fixation point, each at an azimuth of $49^{\circ}$ and an elevation of $17.7^{\circ}$ from fixation (see Figure 1).

In Experiment 1A, the auditory cue was a $2000-\mathrm{Hz}$ pure tone presented at $82 \mathrm{~dB}(\mathrm{~A})$, as measured from the participant's ear position, and the target consisted of a white noise burst at $75 \mathrm{~dB}(\mathrm{~A})$. In Experiment $1 \mathrm{~B}, 5$ of the participants were likewise presented with the pure-tone cue followed by the white-noise target (but both sounds were now presented at $82 \mathrm{~dB}[\mathrm{~A}]$ ), and the remaining 5 participants were presented with a white-noise cue followed by a pure-tone target. ${ }^{1}$ Each cue and target stimulus was presented for $100 \mathrm{msec}$ from two loudspeakers on one or the other side of the participant. Both cue and target sounds gave the phenomenal impression of having 


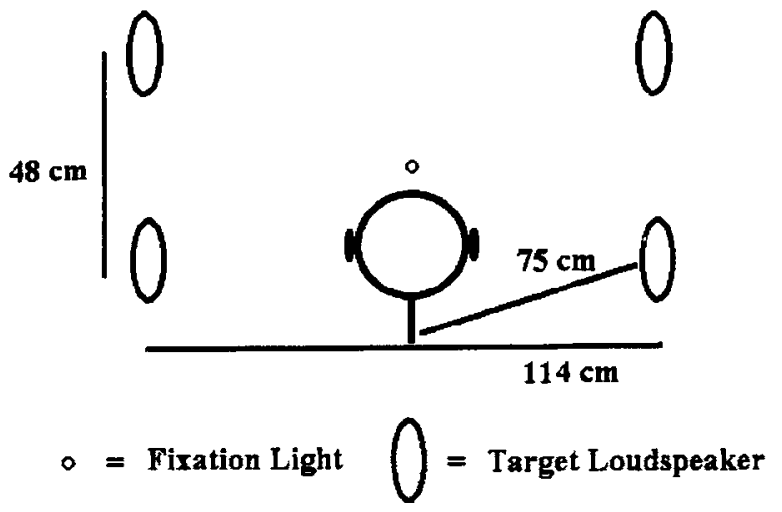

Figure 1. Schematic view of the position of the fixation light and the loudspeaker cones used in Experiment 1, as seen from a raised position behind the participant's head.

been presented from a single source situated midway between the pair of loudspeakers on the side that was used to present the stimuli (i.e., the sounds seemed to be at ear level on one or the other side). Columns of loudspeakers on either side were used in our initial studies rather than a single loudspeaker at ear level on either side due to other ongoing experiments in our laboratory. Participants were required to press a microswitch attached to the table directly in front of them as soon as they detected the onset of a target, and witheld any response to the cues.

Design. There were two within-participant factors. First, the SOAs between cue and target were $100,500,700$, or $900 \mathrm{msec}$ in Experiment 1A, and 100, 400,600, or $900 \mathrm{msec}$ in Experiment $1 \mathrm{~B}$. (The SOAs for Experiment $1 \mathrm{~B}$ were chosen so that the cue-target interval in some trials would exactly match the target-target interval in other trials, as explained below.) The second cue-target factor was whether the cue was ipsilateral or contralateral to the target. These factors were crossed to yield eight equiprobable conditions. Participants completed 60-70 practice trials. These were followed by three test blocks of 160 trials in Experiment $1 \mathrm{~A}$ and by four such test blocks in Experiment 1B.

Procedure. The fixation light was illuminated at the beginning of each trial and remained on until a response was made. Participants were instructed prior to the experiment, and periodically throughout, to maintain fixation on this central yellow LED whenever it was illuminated (fixation was monitored in our later experiments). After a delay of $300 \mathrm{msec}$, the cue was presented from either the left or the right. After a further delay (depending on cue-target SOA), the target was presented from either the ipsilateral or the contralateral side to the cue, which was equiprobable. Participants were informed that the cue was spatially uninformative with regard to the likely target location and so should be ignored. They were also instructed to respond as rapidly as possible without making anticipatory responses. If participants made an anticipatory response within $100 \mathrm{msec}$ of target onset or failed to make a response before the trial was terminated $(1,000 \mathrm{msec}$ after target onset in Experiment $1 \mathrm{~A}$ and $500 \mathrm{msec}$ after target onset in Experiment $1 \mathrm{~B}$ ), the feedback signal was presented. This consisted of three LEDs (the fixation light together with two LEDs arrayed horizontally $3.3^{\circ}$ to either side of fixation) flickering for $270 \mathrm{msec}$. Following a response in Experiment $1 \mathrm{~A}$, the fixation light was turned off for $500 \mathrm{msec}$ before coming on again to start the next trial. In Experiment 1B, the cue on the next trial was presented $500 \mathrm{msec}$ after the onset of the target on the preceding trial (i.e., at the end of the response window). The time window for allowable responses in Experiment 1B was made much narrower so that the cue for the next trial could be presented earlier after the preceding target; thus target-target intervals on some trials (those with 100 - and $400-\mathrm{msec}$ cue-target SOAs) exactly matched cue-target intervals on other trials in this study (those with cue-target SOAs of 600 and $900 \mathrm{msec}$ ). This allowed a direct comparison of any cue-target effects against target-target SOAs for identical intervals between the successive stimuli involved.

\section{Results and Discussion}

Participants made incorrect responses on $1 \%$ of trials in Experiment $1 \mathrm{~A}$ and $15 \%$ in Experiment $1 \mathrm{~B} .^{2}$ These trials were excluded from the RT analysis, as were all trials immediately succeeding an incorrect response because of the variability they can introduce. Table 1 shows mean RTs for trials with ipsilateral and contralateral cues at the different cue-target SOAs in Experiments $1 \mathrm{~A}$ and $1 \mathrm{~B}$.

Cue-target analyses. The mean auditory RT data from Experiments $1 \mathrm{~A}$ and $1 \mathrm{~B}$ were separately subjected to twoway within-participant analyses of variance (ANOVAs) SOA (4) $\times$ cue side (2). These revealed that participants responded to auditory targets more slowly when these were presented on the same side as an uninformative auditory cue than when cue and target events were presented on opposite sides; that is, there was a main effect of cue side $[F(1,8)=13.7, p=.006$, for Experiment $1 \mathrm{~A} ; F(1,9)$ $=8.1, p=.02$, for Experiment $1 \mathrm{~B}]$. The interaction between cue side and SOA also reached significance in Experiment $1 \mathrm{~A}[F(3,24)=3.4, p=.03]$ because the in-

Table 1

Mean Reaction Times, Standard Errors, and Mean Inhibitory Effects (in Milliseconds) for Auditory Targets in Experiment 1 as a Function of Cue Side and Cue-Target Stimulus Onset Asynchrony (SOA)

\begin{tabular}{|c|c|c|c|c|c|c|c|c|c|c|}
\hline \multirow[b]{3}{*}{ SOA } & \multicolumn{4}{|c|}{ Experiment $1 \mathrm{~A}$} & \multirow{3}{*}{$\begin{array}{c}\text { Mean } \\
\text { Inhibitory } \\
\text { Effect }\end{array}$} & \multicolumn{4}{|c|}{ Experiment IB } & \multirow{3}{*}{$\begin{array}{c}\text { Mean } \\
\text { Inhibitory } \\
\text { Effect }\end{array}$} \\
\hline & \multicolumn{2}{|c|}{$\begin{array}{l}\text { Ipsilateral } \\
\text { Cue } \\
\end{array}$} & \multicolumn{2}{|c|}{$\begin{array}{c}\text { Contralateral } \\
\text { Cue }\end{array}$} & & \multicolumn{2}{|c|}{$\begin{array}{l}\text { Ipsilateral } \\
\text { Cue }\end{array}$} & \multicolumn{2}{|c|}{$\begin{array}{c}\text { Contralateral } \\
\text { Cue } \\
\end{array}$} & \\
\hline & $M$ & $\overline{S E}$ & $M$ & $S E$ & & $M$ & $S E$ & $M$ & $S E$ & \\
\hline 100 & 341 & 14 & 335 & 12 & 6 & 338 & 15 & 335 & 15 & 3 \\
\hline 400 & & & & & & 230 & 9 & 231 & 10 & -1 \\
\hline 500 & 252 & 19 & 234 & 17 & 18 & & & & & \\
\hline 600 & & & & & & 221 & 9 & 211 & 8 & $10^{*}$ \\
\hline 700 & 243 & 22 & 231 & 20 & $12+$ & & & & & \\
\hline 900 & 253 & 25 & 233 & 21 & $20^{\dagger}$ & 227 & 11 & 222 & 11 & 5 \\
\hline
\end{tabular}


hibitory effects were more pronounced at the longer SOAs (see Table 1), as in Tassinari and Berlucchi's (1995) study. The lack of any facilitatory effect at the shorter SOA adds to the list of null effects for facilitatory spatial cuing on simple auditory detection latencies, when sounds are presented from peripheral loudspeaker cones (see Spence \& Driver, 1994, for review and discussion of this point). The analysis of Experiments $1 \mathrm{~A}-1 \mathrm{~B}$ also revealed that participants responded more rapidly as cue-target SOA increased, producing a main effect of SOA $[F(3,24)=$ $42.8, p<.0001$, Experiment $1 \mathrm{~A} ; F(3,27)=104.5, p<$ .0001 , Experiment $1 \mathrm{~B}]$. This effect was present in all the subsequent analyses in this paper that include SOA as a factor; it presumably reflects the well-known temporal warning effect (see, e.g., Niemi \& Näätänen, 1981), and so is not considered further.

Target-target analyses. We also conducted intertrial analyses to look for any inhibitory effects between successive ipsilateral targets, which, if found, would allow us to rule out a purely manual response inhibition explanation of the observed IOR (see Maylor \& Hockey, 1985; Posner et al., 1984; Tassinari et al., 1989; Terry et al., 1994, for previous applications of this argument to unimodal visual experiments). The mean RTs from these target-target analyses are shown in Table 2, pooled across cue-target SOA. A two-way within-participant ANOVA was conducted on the data from Experiment $1 \mathrm{~A}$ with the factors of target side relative to the previous target (ipsilateral vs. contralateral) and cue side (ipsilateral vs. contralateral). In the analysis of the data from Experiment 1B, there was also the additional factor of cue-target SOA (short vs. long; note that for Experiment $1 \mathrm{~B}$, only data from the 100 - and 400 -msec cuetarget SOAs were analyzed because at these SOAs, the target-target intervals exactly matched the cue-target intervals for the 600- and 900-msec SOAs, respectively, and these temporal intervals had yielded an inhibitory effect for targets ipsilateral to the preceding cue. For Experiment $1 \mathrm{~A}$, the data were simply pooled across all cue-target SOAs, since none were designed specifically to match any target-target SOAs).

The analysis of both experiments indicated that auditory detection latencies were not reliably influenced by the location of the target on the previous trial, as shown by the fact that target side was not a significant factor in either analysis $[F(1,8)=2.1, p=.18$, Experiment $1 \mathrm{~A} ; F(1,9)=$ $1.8, p=.21$, Experiment $1 \mathrm{~B}]$. Participants did not respond more rapidly on trials in which the preceding target was contralateral than when it was ipsilateral, even though the target-target intervals that were analyzed for Experiment 1B matched the cue-target intervals that had produced inhibitory effects from contralateral cues. The main effect of cue side reached significance in Experiment $1 \mathrm{~A}[F(1,8)=$ $11.7, p=.009$ ], with participants responding more rapidly on contralateral trials, which merely confirms the cue-target IOR effect previously documented. There was no such main effect of cue side in the restricted analysis for Experiment $1 \mathrm{~B}$ because only the two shorter cue-target SOAs were included in this target-target analysis, for the reasons given, and the inhibitory effect from the cue has yet to emerge at the short intervals.

The failure to demonstrate any target-target inhibitory effects means that the inhibitory effect observed in the cue-target analysis of Experiments 1A-1B, and likewise in Tassinari and Berlucchi's (1995) preliminary study, may reflect nothing more than spatially specific manual response inhibition for the cue. Note that since the intensity of cues and targets, and the particular sounds used for them, were matched or counterbalanced in Experiment $1 \mathrm{~B}$, the different effects of cues and of targets cannot be attributed to such factors. Our null target-target effects for audition stand in contrast to the clear inhibitory effect demonstrated for successive ipsilateral visual targets in several previous visual studies, even with an intervening cue event (e.g., Maylor \& Hockey, 1985; Tassinari et al., 1989; Terry et al., 1994). Furthermore, a pilot study of our own, in which visual cue and target stimuli were presented at the same eccentricities as for Experiments $1 \mathrm{~A}-1 \mathrm{~B}$, revealed both clear cue-target inhibitory effects and comparable target-target inhibitory effects within vision. Thus, the most parsimonious account for the present contrast between ipsilateral cue-target inhibition, on the one hand, and null target-target effects, on the other, seems to be that inhibitory effects in the cue-target situation may merely be due to manual response inhibition for the cue (see Harvey, 1980; Maylor \& Hockey, 1985; Posner et al., 1984; Tassinari et al., 1989; Terry et al., 1994) in the auditory case, rather than due to "true" auditory IOR.

\section{EXPERIMENT 2}

Given the difficulty of interpreting cue-target inhibitory effects, as highlighted earlier, we next adopted a continuous responding paradigm in which no peripheral cues were ever presented in order to further examine any pos-

Table 2

Mean Reaction Times, Standard Errors, and Mean Inhibition of Return (IOR) Effects (in Milliseconds) for Auditory Targets in Experiment 1 as a Function of the Preceding Target Side and the Cue Side

\begin{tabular}{|c|c|c|c|c|c|c|}
\hline \multirow[b]{3}{*}{ Experiment } & \multirow{3}{*}{$\begin{array}{l}\text { Cue } \\
\text { Side }\end{array}$} & \multicolumn{4}{|c|}{ Preceding Target Side } & \multirow{3}{*}{$\begin{array}{c}\text { Mean IOR } \\
\text { Effect }\end{array}$} \\
\hline & & \multicolumn{2}{|c|}{ Ipsilateral } & \multicolumn{2}{|c|}{ Contralateral } & \\
\hline & & $M$ & $S E$ & $M$ & $\overline{S E}$ & \\
\hline \multirow[t]{2}{*}{$1 \mathrm{~A}$} & Ipsilateral & 268 & 18 & 275 & 20 & -7 \\
\hline & Contralateral & 257 & 17 & 260 & 17 & -3 \\
\hline \multirow[t]{2}{*}{$1 \mathrm{~B}$} & Ipsilateral & 285 & 22 & 283 & 21 & 2 \\
\hline & Contralateral & 274 & 20 & 291 & 24 & -17 \\
\hline
\end{tabular}

Note-Negative values for the mean IOR effect imply a numerical advantage for ipsilateral targets. 
sible target-target effects. An additional change was that we now used a central audiovisual fixation event at the beginning of every trial, rather than the purely visual fixation event from Experiments 1A-1B. The rationale for this was that, as noted earlier, some researchers have argued that visual IOR effects are more pronounced when a central event occurs after the peripheral event that induces the IOR, in order to direct attention back to fixation prior to the probe event. One might suggest that the purely visual central event in Experiments 1 A-1B may have been inadequate to reorient auditory attention, especially since Spence and Driver (1997a) have argued that visual events have no effect on auditory covert orienting, whereas auditory events result in both auditory and visual orienting (see Spence \& Driver, in press). On the basis of this argument, the new audiovisual central event should be capable of pulling exogenous auditory attention back to the center, which might reveal IOR.

Participants were given up to $500 \mathrm{msec}$ to respond before the onset of the audiovisual fixation event initiated the next trial. Given the results of Experiments 1A-1B, we predicted no IOR between successive auditory targets. That is, response latencies should be unaffected by the relative position of the target on the previous trial. On the other hand, if the null target-target effect in Experiments $1 \mathrm{~A}-1 \mathrm{~B}$ was due to the absence of a central auditory reorienting event, target-target IOR might now be found in audition for the first time.

In order to ensure that our design was appropriate for measuring IOR (given that our auditory stimuli were presented at eccentricities far in excess of those previously studied in the visual literature in order to ensure appropriate auditory localization), we also ran a second group of participants who were presented with eccentric visual targets only, under otherwise comparable conditions. On the basis of the visual pilot study described earlier, plus the visual target-target data from previous studies (e.g., Maylor \& Hockey, 1985; Posner et al., 1984; Tassinari et al., 1989; Terry et al., 1994), we predicted that clear IOR should be seen between successive visual targets, in contrast to the null result predicted for auditory targets on the basis of Experiments $1 \mathrm{~A}-1 \mathrm{~B}$.

\section{Method}

Participants. Thirty participants ( 16 men and 14 women) were recruited, 7 of whom had taken part in one of the preceding exper- iments. The mean age for participants was 24 years, with a range of 17-29 years, and all except 2 were right-handed. Twenty-two of the participants were presented with just auditory targets, and the remaining 8 were presented with visual targets only.

Apparatus, Materials, and Design. These were as in the previous experiment, with the following exceptions. There was now just one loudspeaker cone situated at ear level on either side of the participant to present auditory white-noise targets. These were at the same eccentricity (i.e., $49^{\circ}$ ) as the columns of two loudspeakers (both used in the preceding studies). The visual targets consisted of the illumination of a single bright red LED (RS 587030 ); one of these was attached to the front of each loudspeaker. All targets were presented for $50 \mathrm{msec}$. The visual component of the central event now consisted of the illumination of a central five-LED display panel. These LEDs were arrayed horizontally at ear level directly in front of the participant, with adjacent LEDs separated by $1.6^{\circ}$. The extra central lights were added to make the central reorienting event maximally salient. Participants were instructed to fixate the central LED in the row of five throughout (the central LED was red and the four surrounding LEDs were green). A loudspeaker located just above it presented a $2000-\mathrm{Hz}$ tone simultaneously with the central visual event at the start of each trial, together constituting the audiovisual fixation event. The error signal consisted of ten 20 -msec flashes from the five-light central display panel, each separated by a 40-msec gap.

Procedure. Every trial began with the presentation of the central audiovisual fixation event. The target was presented unpredictably 400 or $800 \mathrm{msec}$ later (to prevent anticipations). We used a mixed design, with the between-participant factor being that some participants were presented with only auditory white-noise targets from either side, and others with only visual targets from either side. Trials were presented in pairs, with the first trial occurring $3,500 \mathrm{msec}$ after the onset of the final target from the preceding pair of trials and the second trial starting $500 \mathrm{msec}$ after the presentation of the target in the previous trial that began the current pair. There were thus two possible target-target intervals within each pair of targets ( 900 or $1,300 \mathrm{msec}$ ), and similarly two intervals for successive targets from different pairs of trials $(3,900$ or $4,300 \mathrm{msec})$. Participants performed 60 practice trials, followed by two blocks of 120 test trials each.

\section{Results}

Due to participants failing to make a correct response within the required time window, $4.5 \%$ of trials were removed from analysis. The mean RTs after these exclusions are shown in Table 3. The mean RT data were subjected to a mixed ANOVA, with the between-participant factor of target modality (auditory or visual) and two within-participant factors. One factor was SOA (short vs. long; short was the 900 - plus the 1,300-msec SOA, and long was the 3,900-plus the 4,300-msec SOA; neigh-

Table 3

Mean Reaction Times, Standard Errors, and Mean Inhibition of Return (IOR) Effects (in Milliseconds) for Auditory and Visual Targets in Experiment 2 as a Function of the Stimulus Onset Asynchrony (SOA) Between Successive Target Events and the Preceding Target Side

\begin{tabular}{|c|c|c|c|c|c|c|c|c|c|c|}
\hline \multirow{4}{*}{$\begin{array}{l}\text { Target } \\
\text { Modality }\end{array}$} & \multicolumn{5}{|c|}{$\begin{array}{c}\text { Short SOAs } \\
\text { (900 and } 1,300 \mathrm{msec} \text { ) }\end{array}$} & \multicolumn{5}{|c|}{$\begin{array}{c}\text { Long SOAs } \\
(3,900 \text { and } 4,300 \text { msec })\end{array}$} \\
\hline & \multicolumn{4}{|c|}{ Target Side } & \multirow{3}{*}{$\begin{array}{l}\text { Mean IOR } \\
\text { Effect }\end{array}$} & & Targ & Side & & \multirow{3}{*}{$\begin{array}{l}\text { Mean IOR } \\
\text { Effect }\end{array}$} \\
\hline & \multicolumn{2}{|c|}{ Ipsilateral } & \multicolumn{2}{|c|}{ Contralateral } & & \multicolumn{2}{|c|}{ Ipsilateral } & \multicolumn{2}{|c|}{ Contralateral } & \\
\hline & $M$ & $S E$ & $M$ & $S E$ & & $M$ & $S E$ & $M$ & $S E$ & \\
\hline Visual & 304 & 14 & 265 & 10 & $39^{*}$ & 264 & 11 & 265 & 7 & -1 \\
\hline Auditory & 233 & 10 & 231 & 9 & 2 & 223 & 8 & 219 & 9 & 4 \\
\hline
\end{tabular}

${ }^{*} p<.01$, by $t$ test pairwise comparison. 
boring SOAs were paired in this way for simplification, after initial analyses had revealed no differences between them). The second within-participant factor was target side (ipsilateral vs. contralateral to the preceding target). There was a main effect of target side $[F(1,28)=25.1$, $p<.0001]$, revealing that participants responded more slowly on ipsilateral trials than on contralateral trials overall, suggesting an IOR effect. Crucially, target side interacted with target modality $[F(1,28)=14.2, p=$ $.0008]$, and subsequent analyses of simple effects revealed that significant IOR occurred for visual targets as a function of preceding target side [mean ipsilateral minus contralateral effect of $19 \mathrm{msec}, F(1,28)=13.1$, $p=.001$ ], but not for auditory target pairs [mean difference of only $3 \mathrm{msec}, F(1,28)=.7$, n.s.). This target-target IOR for visual targets was present only at the shorter SOA, as revealed by the SOA $\times$ target side interaction $[F(1,28)=43.7, p<.0001]$ and by the target modality $\times$ SOA $\times$ target side interaction $[F(1,28)=52.3, p<$ .0001 ; see significance of IOR effects shown in Table 3]. Participants also responded more rapidly to auditory targets than to visual targets, resulting in a main effect of target modality $[F(1,28)=8.8, p=.006]$.

\section{Discussion}

These results demonstrate that response latencies to visual targets are longer when they appear on the ipsilateral rather than the contralateral side to the visual target that had appeared about a second before, replicating previous visual findings (Maylor \& Hockey, 1985; Tassinari et al., 1989; Terry et al., 1994). In contrast, auditory detection was unaffected by the position of the auditory target on the previous trial under comparable conditions, replicating the null results of the auditory target-target analyses from Experiments $1 \mathrm{~A}-1 \mathrm{~B}$, but now in the presence of a intervening central audiovisual event. Thus, on the basis of the previous experiments, there is no target-target evidence to support the claim that presenting an auditory event on one side inhibits responding to subsequent ipsilaterally presented auditory targets, due to auditory IOR. Instead, we have a consistently null finding (except for the cue-target case in Experiments 1A-1B, which may involve manual response inhibition, as discussed earlier). By contrast, IOR was clearly demonstrated between successive visual targets under comparable conditions. We discuss the implications of the null effect for successive auditory targets more thoroughly in the General Discussion.

\section{EXPERIMENT 3}

In the final study, we turned to examine any crossmodal, audiovisual IOR between successive auditory and then visual targets, and also between successive visual and then auditory targets. As noted in the introduction, several researchers have failed to find any inhibitory effects between auditory cues and subsequent visual targets (Farah et al., 1989; Klein et al., 1987; Spence
\& Driver, 1997a). This may have been due to the limited range of SOAs they used or to the failure to present a central cuing event between the onset of the cue and target to draw attention back to fixation prior to target presentation (see Posner \& Cohen, 1984; Terry et al., 1994). We overcame both of these concerns by using a greater range of SOAs and by presenting an audiovisual central event between successive targets (as in Experiment 2) to ensure that attention would be exogenously directed back to fixation.

Prior results regarding the reverse cross-modal effect-possible IOR between a visual event and a subsequent auditory target-have produced more mixed results. Klein et al. (1987) reported a null cue-target effect at SOAs up to $500 \mathrm{msec}$, whereas Reuter-Lorenz et al. (1996) reported inhibitory cue-target effects at longer SOAs after the cue. However, as discussed earlier, the cue-target results of the Reuter-Lorenz et al. study may merely reflect manual response inhibition for the cue, rather than the "true" IOR that might be found with a target-target measure. As in our previous study, we presented only target stimuli in the next experiment (i.e., no peripheral cues were presented) to ensure that any effects could be attributed only to IOR and not to manual response inhibition for the cue. One might reasonably ask whether response inhibition to our audiovisual central event could also cause any IOR-like effects. However, note that this fixation event was presented centrally, and so should not bias responding to either side differentially. Moreover, any suggestion of "cuing" effects from the central event would not explain why in the previous study (Experiment 2), IOR between successive targets was demonstrated only for visual detection, and not for auditory detection, since the same central event was presented in both cases.

We used a design almost identical to that described in Experiment 2, the only difference being that now auditory and visual targets were randomly intermingled for each participant in equal proportions, rather than being presented to separate groups. This allowed us to look at IOR effects between all possible pairings of successive auditory and visual targets. Given the results of Experiment 2, as well as previous findings (Maylor \& Hockey, 1985; Posner et al., 1984; Tassinari et al., 1989; Terry et al., 1994), we expected to find target-target IOR effects between successive visual targets. As discussed earlier, the oculomotor priming explanation for IOR (Rafal et al., 1989; Rafal et al., 1994) and the oculomotor suppression hypothesis both predict that IOR should also occur for the other three possible combinations of successive targets (i.e., auditory-visual, visual-auditory, and auditoryauditory). However, recall that the intramodal auditory target-target effect was not found in Experiments 1 A-1B or 2 , a point to which we return later. Finally, in the previous experiments, we merely instructed subjects to maintain central fixation throughout each trial. To ensure that any effects observed could not be due to occasional saccades, we monitored the horizontal position of 
the left eye for half the participants in our final study, thus ensuring that central fixation was maintained throughout as instructed.

\section{Method}

Fourteen participants ( 7 men and 7 women) took part in this experiment; all except 3 were right-handed. Eleven participants had taken part in one of the preceding experiments. Their mean age was 22 years, with a range of 16-29 years. Each participant completed 50 practice trials followed by two blocks of 240 test trials each. The apparatus, design, method, and procedure were exactly as in Experiment 2 except for the random intermingling of targets from different modalities. The horizontal position of the left eye of 7 participants was monitored automatically by means of an Eye-Trac 210 infrared monitor (Applied Science Laboratories), which was calibrated to provide a signal to the computer whenever the eye deviated more than $3^{\circ}$ to the left or the right of fixation (remember that lateral cues and targets were $49^{\circ}$ from central fixation). The eye monitor was recalibrated to confirm true straight-ahead at the beginning of every block and also during a block if fixation ever drifted from the calibrated center point. Trials when eye movements signals occurred between the onset of the central event and a response being made were automatically discarded. Blinks sometimes caused eye movement signals identical to those produced by a real eye movement, and these trials were also removed from the analysis.

\section{Results}

Due to participants failing to make an appropriate response in the requisite time window, $5.9 \%$ of trials were removed from the analysis, and $10.5 \%$ were removed due to a suspected eye movement for those participants whose eyes were monitored. The means of the participants' RTs are shown in Table 4, pooled across the between-participants factor of eye movement monitoring, which did not affect the results. Closely neighboring target-target SOAs were pooled as in Experiment 2 (i.e., $900 \mathrm{msec}$ with $1,300 \mathrm{msec}$, and $3,900 \mathrm{msec}$ with $4,300 \mathrm{msec}$ ) after preliminary analyses revealed no differences between them.

A mixed ANOVA was carried out on the mean RT data with the between-participants factor of whether eye movements were monitored, and four within-participant factors-SOA (2) $\times$ target modality $(2) \times$ previous target modality (2) $\times$ target side (2). This revealed that participants responded more rapidly overall when targets were contralateral rather than ipsilateral to the preceding target $[F(1,12)=37.9, p<.0001]$, suggesting an IOR effect. The interaction between SOA and preceding target side was significant $[F(1,12)=37.2, p=.0001]$. Pairwise comparisons ( $t$ tests) revealed that mean response latencies on ipsilateral target trials were significantly greater than on contralateral trials only at the short SOAs, as found for vision in Experiment 2 (mean ipsilateral minus contralateral effect of $24 \mathrm{msec}, p<.01$, at the short SOAs, compared with $4 \mathrm{msec}$, n.s., at the long SOAs). In fact, significant IOR was now found at the short SOAs for every combination of modalities for successive targets (see significance levels of mean IOR effects in Table 4).

Visual targets resulted in significantly greater IOR ( $p<.01$ in a $t$-test pairwise comparison) on the following trial than did auditory targets at the shorter SOAs, regardless of the subsequent target modality, as revealed by the interactions between target side and previous target modality $[F(1,12)=7.3, p=.02]$, and among target side, previous target modality, and SOA $[F(1,12)=5.2$, $p=.04]$. This can be seen clearly in Table 4, where IOR effects at the short SOAs are largest on the first and third rows of the table (i.e., where the previous target modality was visual). This means that, at the short SOAs ( 900 and $1,300 \mathrm{msec}$ ), where IOR was evident for all combinations of successive targets, the size of the IOR effect was critically determined by the "cuing" event (i.e., by the preceding target), and not by the nature of the target used to measure it [as shown by the failure of the fourway SOA $\times$ previous target modality $\times$ target modality $\times$ target side interaction to reach significance, $F(1,12)=$ $1.5, p=.25]$.

The interaction between the target modality and the previous target modality was significant $[F(1,12)=9.3$, $p=.01]$, and these factors also interacted with SOA $[F(1,12)=6.7, p=.02]$. Pairwise comparisons ( $t$ tests) revealed that these interactions were caused by auditory responses being faster following an auditory target than following a visual target, at just the short SOA $(p<.05)$. This result presumably reflects the well-known modalityshift effect (see, e.g., Dinnerstein \& Zlotogura, 1968; Ferstl, Hanewinkel, \& Krag, 1994; Mowrer, Rayman, \& Bliss, 1940; Spence \& Driver, 1997b; Spence, Driver, \&

Table 4

Mean Reaction Times, Standard Errors, and Mean Inhibition of Return (IOR) Effects (in Milliseconds) for Auditory and Visual Targets for Experiment 3 as a Function of the Stimulus Onset Asynchrony (SOA) Between Successive Target Events and the Preceding Target Side

\begin{tabular}{|c|c|c|c|c|c|c|c|c|c|c|c|}
\hline \multirow{3}{*}{$\begin{array}{l}\text { Previous } \\
\text { Target } \\
\text { Modality }\end{array}$} & \multirow{3}{*}{$\begin{array}{c}\text { Present } \\
\text { Target } \\
\text { Modality }\end{array}$} & \multirow{2}{*}{\multicolumn{4}{|c|}{ Preceding Target Side }} & \multirow{3}{*}{$\begin{array}{c}\text { Mean IOR } \\
\text { Effect }\end{array}$} & \multirow{2}{*}{\multicolumn{4}{|c|}{$\begin{array}{c}\text { Long SOA } \\
(3,900 \text { or } 4,300 \mathrm{msec}) \\
\text { Preceding Target Side }\end{array}$}} & \multirow{3}{*}{$\begin{array}{c}\text { Mean IOR } \\
\text { Effect }\end{array}$} \\
\hline & & & & & & & & & & & \\
\hline & & $M$ & $S E$ & $M$ & $S E$ & & $M$ & $S E$ & $M$ & $\overline{S E}$ & \\
\hline Visual & Visual & 316 & 12 & 285 & 11 & $31^{*}$ & 280 & 9 & 282 & 8 & -2 \\
\hline Visual & Auditory & 299 & 16 & 265 & 14 & $34^{*}$ & 245 & 13 & 239 & 12 & 6 \\
\hline Auditory & Auditory & 264 & 15 & 248 & 14 & $16^{*}$ & 249 & 13 & 236 & 11 & $13^{*}$ \\
\hline
\end{tabular}

${ }^{*} p<.01$, by $t$-test pairwise comparison. 
Rogers, 1997). Response latencies were also significantly shorter for auditory targets overall, as in Experiment 2 , resulting in a main effect of target modality $[F(1,12)=27.7, p=.0002]$.

\section{Discussion}

The results of Experiment 3 show that at short SOAs (900-1,300 msec), detection latencies for both visual and auditory targets were slower when the target on the previous trial occurred in the same position compared with when it was presented from the contralateral side. All combinations of target-target pairings now produced significant IOR at the short SOA. In addition, some IOR was also demonstrated in this study between successive auditory targets at the longer SOA. These effects cannot be attributed to any form of overt orienting, since there was no main effect of eye movement monitoring, nor did this factor interact with any of the others. The finding that visual target detection is impaired by a preceding visual target in the same location replicates the results of previous visual studies of target-target IOR (e.g., Maylor \& Hockey, 1985; Posner et al., 1984; Tassinari et al., 1989; Terry et al., 1994; the present Experiment 2). However, the cross-modal finding that an auditory target also impairs responding to a subsequent visual target on the same side contrasts with previous null cross-modal effects (Farah et al., 1989; Klein et al., 1987; Spence \& Driver, 1997a), although those previous studies may have been insensitive to IOR for the reasons discussed earlier. The further finding of reliable target-target IOR for the reverse cross-modal situation (a visual event preceding an auditory event) is consistent with ReuterLorenz et al.'s (1996) recent report of cross-modal IOR in this direction and extends their observation to the target-target rather than the cue-target case, thus ruling out accounts in terms of mere manual response inhibition to cue events.

A further, unpredicted, finding of Experiment 3 was that auditory target detection was now impaired by the presentation of an auditory target on the ipsilateral side during the preceding trial. This result stands in contrast to the preceding two experiments. The only difference between Experiments 2 and 3 was that auditory targets were presented in unimodal blocks in Experiment 2 (i.e., the auditory group of participants received only sound targets), whereas both auditory and visual targets were presented in Experiment 3, in an unpredictable intermingled fashion. This implies that uncertainty regarding the target modality may be the critical factor determining whether target-target auditory IOR will be observed, as we discuss at length later.

One interpretation of our finding that the size of the target-target IOR effects was larger following a visual target than following an auditory target would be that visual events generally result in greater IOR than do auditory events. One possible reason for this may be related to the fact that people typically cannot localize auditory stimuli as accurately as visual stimuli. As a consequence, any IOR elicited by an auditory event might be less focused than that induced by a more localizable visual event, resulting in a smaller IOR effect following auditory targets overall. However, it is also possible that the relative intensity of auditory and visual stimuli may have a role in the size of any IOR effects observed (i.e., IOR might be dependent solely on the intensity of the event causing it, with the particular visual events that we used just happening to be more salient than the auditory events used). This possibility cannot be ruled out since no attempt was made to equate the intensity of the auditory and visual targets. Nevertheless, our main point remains that it is apparently the initiating event (in our case, the preceding target) that determines the overall size of the IOR effect, and not the event used to measure it (i.e., the subsequent target). This accords with existing accounts of IOR as an effect that is automatically initiated by the preceding event, rather than as a "backward" effect that might be triggered primarily by the subsequent event (as in recent accounts for other attentional effects between successive stimuli, which invoke matching processes, e.g., Kahneman, Treisman, \& Gibbs, 1992, or retrieval processes, e.g., Neill, Valdes, Terry, \& Gorfein, 1992, thought to be triggered by the second event in a successive pair).

\section{GENERAL DISCUSSION}

\section{Modality Uncertainty and Auditory IOR}

There was a clear contrast between the null effects reported for successive auditory targets in Experiments $1 \mathrm{~A}-1 \mathrm{~B}$ and 2 and the reliable intramodal targettarget IOR effects found in audition for Experiment 3. It is difficult to make appropriate comparisons between Experiments 1A-1B and Experiment 3 because of the numerous differences in design. However, the design of Experiment 2 was identical to that of Experiment 3, except for the inclusion of an intermingled $50 \%$ of visual targets in only the latter two studies. Comparison of the confidence intervals for the null auditory target-target effect in Experiment 2, versus the reliable IOR effect for this same condition in Experiment 3, confirms that the difference in outcome between the experiments is genuine (the $95 \%$ confidence limits for the null target-target auditory effect at the short interval in Experiment 2 place it between -3.8 and $+7.6 \mathrm{msec}$; the confidence limits for the auditory target-target IOR effect in Experiment 3 place it between +24.2 and $+7.8 \mathrm{msec}$ ).

Of course, it is always difficult to base any conclusions on null findings, such as the repeatedly null targettarget auditory IOR effects in Experiments 1A-1B and 2, in which target modality was certain. Frick (1995) has recently suggested some useful criteria that should be met before any interpretations can be based on a null effect. We hope to have satisfied all of these, as follows. First, we made repeated attempts to show an inhibitory effect between successive ipsilateral auditory targets, when target modality was certain (Experiments 1A-1B and 2). We have also conducted several other variations 
(not reported here) that similarly yielded a null result between successive auditory targets under unimodal conditions. Second, these null target-target auditory effects (with target modality certain) were found in the context of positive effects-both within vision under comparable circumstances (Experiment 2) and within hearing when target modality was uncertain (Experiment 3), or when cue-target effects were analyzed instead of targettarget effects (Experiment 1A-1B). Finally, the confidence intervals surrounding the null effect were small enough to be useful. That is, the null auditory targettarget effect for Experiment 2 was significantly different from the positive effect for the same conditions in Experiment 3 . Thus, we seem to have a reliable null effect between successively presented auditory targets when all targets are auditory. Moreover, this differs significantly from the reliable IOR found between successive auditory targets in Experiment 3, in which the only change was that visual targets were intermingled. Note also that the positive auditory target-target IOR effect with modality uncertain was replicated in Experiment 3, since it was found for both groups that were and were not monitored for eye movement, and was still reliable when each group was analyzed in isolation.

One possible trivial reason for the emergence of auditory-auditory target IOR effects in Experiment 3 might be that auditory RTs in these studies were simply on average longer than those found in Experiment 2 (when auditory targets succeeded an auditory target in Experiment 3, the mean RT was $249 \mathrm{msec}$, compared with $227 \mathrm{msec}$ in Experiment 2). In order to examine whether this trend toward slower auditory detections in Experiment 3 could be responsible for the unexpected emergence of the auditory target-target IOR effect, we conducted a further analysis of the data from Experiment 3. Participants were separated into two groups on the basis of their average RT. The performance of the 7 fastest participants was compared with that of the slowest 7 participants, with the same within-participant factors described for the earlier analysis of Experiment 3, plus the between-participants factor of speed-group (averaged over eye movement monitoring, which had no major effects on the results). This analysis revealed that although the participants in the "faster" group naturally responded more rapidly than those in the "slower" group $[F(1,12)=6.7, p=.02$ (mean RT of $228 \mathrm{msec}$ for the faster group compared with $284 \mathrm{msec}$ for the slower group)], this factor did not interact significantly with any others. Most critically, the speed-group factor did not interact with the IOR effect of target side $[F(1,12)=.1$, n.s.]. Moreover, participants in the faster group of Experiment 3 responded as rapidly to auditory-auditory sequences overall as participants in the unimodal Experiment 2 (means of $228 \mathrm{vs} .227 \mathrm{msec}$, respectively). Thus, it seems that the emergence of auditory target-target IOR in Experiment 3 cannot be explained merely in terms of the absolute overall detection latencies for auditory targets in these studies, as compared with Experiment 2.
The main difference in design between Experiments $1 \mathrm{~A}-1 \mathrm{~B}$ and 2 versus Experiment 3, which was presumably responsible for the contrasting results, is that the modality of targets was certain in the first two experiments, whereas it was entirely unpredictable in the latter. It is not obvious a priori why target modality uncertainty should affect auditory IOR (especially given that IOR to visual targets seems quite unaffected by this factor), and our discussion of this outcome is thus somewhat speculative. Nevertheless, such a discussion does seem justified, both by the consistency of the outcome across our experiments and by suggestive analogies with other results in the attention literature.

In particular, similar differential effects of modality uncertainty on auditory but not visual performance have recently emerged in the event-related potential (ERP) attention literature. Woods, Alho, and Algazi (1992) reported an ERP study that examined the averaged changes in electrical activity against time, as measured by electrodes on the participant's scalp, when stimuli were presented in intermingled bimodal sequences. The participant had to attend to stimuli presented in just one modality in order to detect occasional deviant stimuli occurring in that modality. Woods et al. found that the early component of processing negativity, generated over the auditory cortex during this bimodal task when participants were attending just to auditory targets, differed in both scalp and temporal distribution from that reported in other intramodal studies in which participants were presented only with auditory stimuli (e.g., Näätänen, 1990; see also Alho, Woods, Algazi, \& Näätänen, 1992; Hackley, Woldorff, \& Hillyard, 1990). On the basis of these results, Woods and colleagues have suggested that different brain mechanisms may be involved in the selection of auditory stimuli among a stream of other auditory stimuli (modality-certain condition), versus the selection of auditory stimuli among streams that can include visual stimuli (modality-uncertain condition). More importantly for present purposes, no such electrophysiological differences were reported between intramodal and cross-modal visual conditions, suggesting a possible asymmetry in the effects of modality uncertainty on vision versus audition, as found behaviorally in the present series of experiments.

Furthermore, Wynn (1977) has reported differences in the distribution of simple RTs to auditory versus visual targets. Visual detection latencies show a single-peaked distribution, whereas auditory RTs show a bimodal distribution, leading Wynn to suggest that there may be two routes for the detection of auditory stimuli, but only one route for visual detection. It may be that when targets are consistently just auditory as in Experiments 1 A-1B and 2 , participants can respond on the basis of an early unimodal representation of auditory stimuli, whereas detection for targets in mixed-modality blocks may have occurred at a later multimodal level of representation that is more sensitive to IOR. This is consistent with the trend for faster auditory RTs in Experiment 2 versus Experiment 3 , but note that the modality-shift effect dis- 
cussed earlier (Mowrer et al., 1940; Spence \& Driver, $1997 \mathrm{~b}$ ) might also be responsible.

Indeed, it is possible that detection based on very early representations of auditory stimuli may be insensitive to IOR effects when these are truly caused by oculomotor priming (Rafal et al., 1989; Rafal et al., 1994). Neurophysiological research suggests that activation of saccade programs by peripheral flashes or sounds probably arises at multimodal stages of the superior colliculus (see below), whereas auditory detection could in principle be based on earlier unimodal levels of the auditory system when optimized in unimodal blocks (as in Experiments $1 \mathrm{~A}-1 \mathrm{~B}$ and 2 ). These levels may be relatively insensitive to the distribution of any IOR effects (e.g., because they may involve nonspatial representations).

Detection responses for auditory targets in mixedmodality target blocks (as in Experiment 3 ) might be based on some multimodal representation instead, in which both auditory and visual stimuli are represented. One of the earliest sites of convergence for auditory and visual information is in the superior colliculus (SC), a neural center for saccade generation (see Stein \& Meredith, 1993, for a review) that may also be implicated in IOR (see below). Hence, auditory detection in multimodal blocks might be more sensitive to IOR than auditory detection in unimodal blocks, due to responses being based on earlier levels of auditory representation in the latter case. By contrast, no such influence of modality uncertainty would be expected to emerge for visual detection, since, according to Wynn's (1977) data, there is only one route to visual detection with simple RTs. Although this account is admittedly speculative, it seems consistent with the present findings, with existing ERP data (Woods et al., 1992), and finally with Wynn's suggestion that there may be two routes for auditory detection, but only one for visual detection as measured by simple RTs.

\section{Possible Neural Substrate for Visual, Auditory, and Cross-Modal IOR in the Superior Colliculus}

The mammalian SC forms a key component of a system that ensures the rapid overt orienting of the eyes, head, and body toward new and relevant events (e.g., Dean, Redgrave, Sahibzada, \& Tsuji, 1986; A. Grantyn \& R. Grantyn, 1982; Knudsen, Knudsen, \& Masino, 1993; Peck, 1987). Evidence from several sources suggests that the SC may also be one of the neural substrates underlying IOR between successive visual events (e.g., Posner et al., 1985; Rafal et al., 1989). Rafal et al. (1989) reported that IOR between successive visual "events" is greater following signals presented in the temporal than in the nasal hemifield, whether measured by saccadic latency or by simple manual detection latency. This finding matches the known idiosyncrasy of the retino-tectal visual pathways, whereby more projections lead from the temporal visual field to the SC. Evidence from neurological patients with progressive supranuclear palsy, a degenerative disorder that primarily affects midbrain re- gions including the $\mathrm{SC}$, is also consistent with a collicular role in the control of IOR between successive visual events. Posner et al. (1985) found that collicular degeneration impaired saccade generation and also resulted in a loss of IOR. Finally, single neurons of the SC in a number of species show inhibitory effects from prior stimulation on visually elicited responses (see, e.g., Rizzolatti, Camarda, Grupp, \& Pisa, 1974; Wurtz, Richmond, \& Judge, 1980), which apparently have time courses and spatial distributions that are similar to those documented in human studies of IOR between successive visual events (Berlucchi et al., 1989; Tassinari \& Berlucchi, 1993). Together, these findings suggest that the $S C$ may be a major neural substrate for visual IOR.

Could the SC also be involved in the auditory and audiovisual IOR effects reported in the present Experiment 3? Neurophysiological studies have convincingly demonstrated in several species that the $\mathrm{SC}$ is a multimodal center for the generation and control of saccadic eye movements to both visual and auditory stimuli (Sparks \& Mays, 1981; Wurtz \& Albano, 1980). The SC is a bipartite structure consisting of primarily visual superficial layers, plus deeper multimodal layers that receive visual, auditory, and somatosensory inputs (see R. Grantyn, 1988, Guitton, 1991, and Stein \& Meredith, 1993, for reviews). Moreover, in the deeper layers, many neurons have motor-related discharges that precede eye movements (i.e., saccade-related burst neurons, or SRBNs). SRBNs have no sensory responses per se, but discharge a high-frequency burst of action potentials immediately prior to saccades, consisting of signals in motor coordinates specifying the metrics of an eye movement. The majority of SRBNs discharge before saccades to both auditory and visual targets (Jay \& Sparks, 1984, 1987), with very few bursting before only one of these (Guitton, 1991).

Behavioral evidence from human participants also converges on the conclusion that there are strong audiovisual links in the generation of saccades. Fendrich, Hughes, and Reuter-Lorenz (1991) studied the facilitation of saccadic latency caused by fixation-point offset just prior to the onset of a peripheral target requiring foveation (i.e., the "gap" effect). This effect has recently been attributed to activity in the SC in monkeys (Dorris \& Munoz, 1995). Fendrich et al. found that the gap effect arises for saccades to both visual and auditory targets in humans. Furthermore, saccade latencies to combined bimodal targets (auditory and visual) with congruent positions are faster than to either when presented alone (Hughes, Reuter-Lorenz, Nozawa, \& Fendrich, 1994; Lee, Chung, Kim, \& Park, 1991; Lueck, Crawford, Savage, \& Kennard, 1990; Perrott, Saberi, Brown, \& Strybel, 1990; see also Engelken \& Stevens, 1989). This pattern of facilitation of saccade RT with coincidental bimodal stimuli is similar to the unit discharge patterns of spatially aligned bimodal cells in the SC, which can show overadditivity of the two unimodal responses (see, e.g., Peck, 1987; Stein, Meredith, \& Wallace, 1993). The be- 
havioral metrics of saccades to auditory and visual targets are also similar (see Fuller, 1992, and Jay \& Sparks, 1990 , for recent reviews). Given all this behavioral evidence for cross-modal links in saccades, together with the neurophysiological evidence for cross-modal interactions in the SC and the evidence for SC involvement in both saccade generation and IOR, the SC seems a very likely candidate for involvement in the present cross-modal IOR effects.

\section{Conclusions}

The present studies revealed auditory-auditory, visualvisual, and cross-modal audiovisual IOR between successive targets, provided that target modality was uncertain (Experiment 3). These target-target results provide the first cases of auditory IOR and of cross-modal IOR that cannot be attributed merely to manual response inhibition for a preceding cue event (cf. Reuter-Lorenz et al., 1996; Tassinari \& Berlucchi, 1995). The results of Experiment 3 are consistent with the proposal that any event that can trigger a saccade should also generate IOR, regardless of its modality, as predicted by Rafal et al.'s (1989; Rafal et al., 1994) oculomotor priming account for IOR. The new auditory and cross-modal findings are also consistent with neuroscience evidence that IOR may arise in the SC, a multimodal structure that is implicated in both saccade generation and in the attentional effects of sudden uninformative events.

Target-target IOR was also found within vision when target modality was known, but was repeatedly absent within audition under these circumstances (Experiments $1 \mathrm{~A}-1 \mathrm{~B}$ and 2). Tentatively, this may be due to participants' basing their detection responses on an earlier representation in hearing when all targets are auditory. Although this account for the effects of modality certainty is speculative, it seems consistent with other sources of evidence. In any case, the mixed-modality paradigm developed in Experiment 3 provides a reliable means of measuring IOR among all combinations of audiovisual events. Hopefully, it can therefore be used to study crossmodal spatial interactions further at a behavioral level, thus allowing a closer comparison with the growing number of such studies at a neurophysiological level (see Stein $\&$ Meredith, 1993). Indeed, we have recently extended this paradigm to show that cross-modal links in IOR extend to all combinations of auditory, visual, and tactile stimuli (Spence, Nicholls, Gillespie, \& Driver, 1997).

\section{REFERENCES}

ABrams, R. A., \& DobKIn, R. S. (1994a). The gap effect and inhibition of return: Interactive effects on eye movement latencies. Experimental Brain Research, 98, 483-487.

Abrams, R. A., \& Dobkin, R. S. (1994b). Inhibition of return: Effects of attentional cuing on eye movement latencies. Journal of Experimental Psychology: Human Perception \& Performance, 20, 467-477.

Alho, K., Woods, D. L., Algazi, A., \& Näätänen, R. (1992). Intermodal selective attention: II. Effects of attentional load on processing of auditory and visual stimuli in central space. Electroencephalography \& Clinical Neurophysiology, 82, 356-368.
Berlucchi, G., Tassinari, G., Marzi, C. A., \& Di Stefano, M. (1989). Spatial distribution of the inhibitory effect of peripheral noninformative cues on simple reaction time to non-fixated visual targets. Neuropsychologia, 27, 201-221.

Bonnel, A.-M., PossamaÏ, C.-A., \& Schmitt, M. (1987). Early modulation of visual input: A study of attentional strategies. The Quarterly Journal of Experimental Psychology, 39A, 757-776.

Cheal, M., Chastain, G., \& Lyon, D. R. (in press). Inhibition of return in visual identification tasks. Visual Cognition.

Chelazzi, L., Biscaldi, M., Corbetta, M., Peru, A., Tassinari, G., \& BERLUCCHI, G. (1995). Oculomotor activity and visual spatial attention. Behavioral \& Brain Science, 71, 81-88.

Dean, P., Redgrave, P., Sahibzada, N., \& Tsuji, K. (1986). Head and body movements produced by electrical stimulation of superior colliculus in rats: Effects of interruption of crossed tectoreticulospinal pathway. Neuroscience, 19, 367-380.

DE Jong, R., Liang, C.-C., \& LAUBER, E. (1994). Conditional and unconditional automaticity: A dual-process model of effects of spatial stimulus-response correspondence. Journal of Experimental Psychology: Human Perception \& Performance, 20, 731-750.

Dinnerstein, A. J., \& Zlotogura, P. (1968). Intermodal perception of temporal order and motor skills: Effects of age. Perceptual \& Motor Skills, 26, 987-1000.

Dorris, M. C., \& Munoz, D. P. (1995). A neural correlate for the gap effect on saccadic reaction-times in monkey. Journal of Neurophysiology, 73, 2558-2562.

EngelKen, E. J., \& Stevens, K. W. (1989). Saccadic eye movements in response to visual, auditory and bisensory stimuli. Aviation, Space \& Environmental Medicine, 60, 763-768.

Farah, M. J., Wong, A. B., Monheit, M. A., \& Morrow, L. A. (1989). Parietal lobe mechanisms of spatial attention: Modality-specific or supramodal? Neuropsychologia, 27, 461-470.

Fendrich, R., Hughes, H. C., \& Reuter-LoRenz, P. A. (1991). Fixation-point offsets reduce the latency of saccades to acoustic targets. Perception \& Psychophysics, 50, 383-387.

Ferstl, R., Hanewinkel, R., \& KraG, P. (1994). Is the modality-shift effect specific for schizophrenia patients? Schizophrenia Bulletin, 2 , 367-373.

FrICK, R. W. (1995). Accepting the null hypothesis. Memory \& Cognition, 23, 132-138.

FULLER, J. H. (1992). Comparison of head movement strategies among mammals. In A. Berthoz, P. P. Vidal, \& W. Graf (Eds.), The headneck sensory motor system (pp. 101-112). New York: Oxford University Press.

Grantyn, A., \& Grantyn, R. (1982). Axonal patterns and sites of termination of cat superior colliculus neurons projecting in the tectobulbo-spinal tract. Experimental Brain Research, 46, 243-265.

GrantyN, R. (1988). Gaze control through superior colliculus: Structure and function. In J. A. Büttner-Ennever (Ed.), Neuroanatomy of the oculomotor system (pp. 273-322). Amsterdam: Elsevier, NorthHolland.

GuitTon, D. (1991). Control of saccadic eye and gaze movements by the superior colliculus and basal ganglia. In R. H. S. Carpenter (Ed.), Eye movements (pp. 244-276). Houndsmill, U.K.: Macmillan.

HaCKLEY, S. A., WoldorfF, M., \& Hillyard, S. A. (1990). Crossmodal selective attention effects on retinal, myogenic, brainstem, and cerebral evoked potentials. Psychophysiology, 27, 195-208.

HARVEY, N. (1980). Non-informative effects of stimuli functioning as cues. Quarterly Journal of Experimental Psychology, 32, 413-425.

Hughes, H. C., Reuter-Lorenz, P. A., Nozawa, G., \& Fendrich, R. (1994). Visual-auditory interactions in sensorimotor processing: Saccades versus manual responses. Journal of Experimental Psychology: Human Perception \& Performance, 20, 131-153.

JAY, M. F., \& SPARKS, D. L. (1984). Auditory receptive fields in primate superior colliculus shift with changes in eye position. Nature, $\mathbf{3 0 9}$, 345-347.

JAY, M. F., \& SPARKS, D. L. (1987). Sensorimotor integration in the primate superior colliculus: 1 . Motor convergence. Journal of Neurophysiology, 57, 22-34.

JAY, M. F., \& SPARKS, D. L. (1990). Localization of auditory and visual targets for the initiation of saccadic eye movements. In M. A. Berkley 
\& W. Stebbins (Eds.), Comparative perception: Vol. I. Basic mechanisms (pp. 351-374). New York: Wiley.

Kahneman, D., Treisman, A., \& GibBs, B. J. (1992). The reviewing of object files: Object-specific integration of information. Cognitive Psychology, 24, 175-219.

Klein, R. M., Brennan, M., \& Gilani, A. (1987, November). Covert cross-modality orienting of attention in space. Paper presented at the annual meeting of the Psychonomic Society, Seattle.

KLEIN, R. M., \& TAYLOR, T. L. (1994). Categories of cognitive inhibition with reference to attention. In D. Dagenbach \& T. H. Carr (Eds.), Inhibitory processes in attention, memory, and language (pp. 113150). New York: Academic Press.

Knudsen, E. I., KNudsen, P. F., \& Masino, T. (1993). Parallel pathways mediating both sound localization and gaze control in the forebrain and midbrain of the barn owl. Journal of Neuroscience, 13 , 2837-2852.

LeE, C., Chung, S., Kim, J., \& PARK, J. (1991). Auditory facilitation of visually-guided saccades. Society for Neuroscience Abstracts, 17, 862.

Lueck, C. J., Crawford, T. J., Savage, C. J., \& Kennard, C. (1990). Auditory--visual interaction in the generation of saccades in man. $E x$ perimental Brain Research, 82, 149-157.

MAYLOR, E. A. (1985). Facilitatory and inhibitory components of orienting in visual space. In M. I. Posner \& O. S. M. Marin (Eds.), Attention and performance XI (pp. 189-204). Hillsdale, NJ: Erlbaum.

MAYLOR, E. A., \& HOCKEY, R. (1985). Inhibitory components of externally controlled covert orienting in visual space. Journal of Experimental Psychology: Human Perception \& Performance, 11, 777-787.

Mowrer, O. H., Rayman, N. N., \& Bliss, E. L. (1940). Preparatory set (expectancy)-An experimental demonstration of its "central" locus. Journal of Experimental Psychology, 26, 357-372.

NÄÄTÄNEN, R. (1990). The role of attention in auditory information processing as revealed by event-related potentials and other brain measures of cognitive function. Behavioral \& Brain Sciences, 13, 201-288.

Neill, W. T., Valdes, L. A., Terry, K. M., \& Gorfein, D. S. (1992). Persistence of negative priming: II. Evidence from episodic trace retrieval. Journal of Experimental Psychology: Learning, Memory, \& Cognition, 5, 993-1000.

NiEMI, P., \& NäÄTÄNEN, R. (1981). Foreperiod and simple reaction time. Psychological Bulletin, 89, 133-162.

PECK, C. K. (1987). Visual-auditory interactions in cat superior colliculus: Their role in control of gaze. Brain Research, 420, 162-166.

Perrott, D. R., Saberi, K., Brown, K., \& Strybel, T. Z. (1990). Auditory psychomotor coordination and visual search performance. Perception \& Psychophysics, 48, 214-226.

PontefraCt, A., \& KLEIN, R. M. (1988). Assessing inhibition of return with simple and choice reaction time. Unpublished manuscript.

Posner, M. I. (1978). Chronometric explorations of mind. Hillsdale, $\mathrm{NJ}$ : Erlbaum

PosNer, M. I., \& Cohen, Y. (1984). Components of visual orienting. In H. Bouma \& D. G. Bouwhuis (Eds.), Attention and performance X: Control of language processes (pp. 531-556). Hillsdale, NJ: Erlbaum.

Posner, M. I., Cohen, Y., Choate, L. S., Hockey, R., \& Maylor, E. (1984). Sustained concentration: Passive filtering or active orienting? In S. Kornblum \& J. Requin (Eds.), Preparatory states and processes (pp. 49-65). Hillsdale, NJ: Erlbaum.

Posner, M. I., Rafal, R. D., Choate, L. S., \& Vaughan, J. (1985). Inhibition of return: Neural basis and function. Cognitive Neuropsychology, 2, 211-228.

PratT, J. (1995). Inhibition of return in a discrimination task. Psychonomic Bulletin \& Review, 2, 117-120.

Pumphrey, R. J. (1950). Hearing. Symposium of the Society for Experimental Biology: Physiological Mechanisms in Animal Behavior, 4, 3-18.

Rafal, R. D., Calabresi, P. A., Brennan, C, W., \& Sciolto, T. K. (1989). Saccade preparation inhibits reorienting to recently attended locations. Journal of Experimental Psychology: Human Perception \& Performance, 15, 673-685.

RaFAL, R. [D.], Egl.y, R., \& Rhodes, D. (1994). Effects of inhibition of return on voluntary and visually guided saccades. Canadian Journal of Experimental Psychology, 48, 284-300.

RAFAL, R. [D.], \& HeNIK, A. (1994). The neurology of inhibition. Integrating controlled and automatic processes. In D. Dagenbach \& T. H. Carr (Eds.), Inhibitory processes in attention, memory, and language (pp. 1-51). New York: Academic Press.

ReUter-LorenZ, P. A., JHA, A. P., \& Rosenquist, J. N. (1996). What is inhibited by inhibition of return? Journal of Experimental Psychology: Human Perception \& Performance, 22, 367-378.

ReUter-Lorenz, P. A., \& RosenQUist, J. N. (1996). Auditory cues and inhibition of return: The importance of oculomotor activation. $E x$ perimental Brain Research, 112, 119-126.

Rizzolatti, G., Camarda, R., Grupp, L. A., \& Pisa, M. (1974). Inhibitory effect of remote visual stimuli on visual responses of cat superior colliculus: Spatial and temporal factors. Journal of Neurophysiology, 37, 1262-1275.

Simon, J. R. (1990). The effects of an irrelevant directional cue on human information processing. In R. W. Proctor \& T. G. Reeve (Eds.), Stimulus-response compatibility (pp. 31-86). Amsterdam: Elsevier, North-Holland.

Simon, J. R., CRAFT, J. L., \& Webster, J. B. (1971). Reaction time to onset and offset of lights and tones: Reactions toward the changed element in a two-element display. Journal of Experimental Psychology, 89, 197-202.

Sokolov, E. N. (1963). Perreption and the conditioned reflex. New York: Macmillan.

SPARKS, D. L., \& MAYs, L. E. (1981). The role of the monkey superior colliculus in the control of saccadic eye movements: A current perspective. In A. Fuchs \& W. Becker (Eds.), Progress in oculomotor research (pp. 137-144). Amsterdam: Elsevier, North-Holland.

SPENCE, C. J., \& DRIVER, J. (1994). Covert spatial orienting in audition: Exogenous and endogenous mechanisms. Journal of Experimental Psychology: Human Perception \& Performance, 20, 555-574.

SPENCE, C. [J.], \& DRIVER, J. (1997a). Audiovisual links in exogenous covert spatial orienting. Perception \& Psychophysics, 59, 1-22.

SPENCE, C. [J.], \& DRIVER, J. (1997b). On measuring selective attention to an expected sensory modality. Perception \& Psychophysics, 59, 389-403.

SPENCE, C. [J.], \& DRIVER, J. (in press). Inhibition of return following an auditory cue: The role of central reorienting events. Experimental Brain Research.

SPENCE, C. [J.], DRIVER, J., \& ROGERs, R. (1997). Is there an attentional component to the modality-shift effect? Manuscript in preparation.

Spence, C. [J.], Nicholls, M. E. R., Gillespie, N., \& Driver, J. (1997). Cross-modal inhibition of return between auditory, visual, and tactile stimuli. Manuscript submitted for publication.

Stein, B. E., \& MEREDITH, M. A. (1993). The merging of the senses. Cambridge, MA: MIT Press.

Stein, B., Meredirh, M. A., \& Wallace, M. T. (1993). The visuallyresponsive neuron and beyond: Multisensory integration in cat and monkey. Progress in Brain Research, 95, 79-90.

tassinari, G., Aglioti, S., Chelazzi, L., Marzi, C. A., \& BerlucCHI, G. (1987). Distribution in the visual field of the costs of voluntarily allocated attention and of the inhibitory after-effects of covert orienting. Neuropsychologia, 25, 55-71.

Tassinari, G., Aglioti, S., Chelazzi, L., Peru, A., \& Berlucchi, G. (1994). Do peripheral non-informative cues induce early facilitation of target detection? Vision Research, 34, 179-189.

Tassinari, G., \& Berlucchi, G. (1993). Sensory and attentional components of slowing of manual reaction time to non-fixated visual targets by ipsilateral primes. Vision Research, 33, 1525-1534.

TAssinari, G., \& Berlucchi; G. (1995). Covert orienting to noninformative cues: Reaction time studies. Behavioural Brain Research, 71, 101-112.

Tassinari, G., Biscaldi, M., Marzi, C. A., \& Berlucchi, G. (1989). Ipsilateral inhibition and contralateral facilitation of simple reaction time to non-foveal visual targets from non-informative visual cues. Acta Psychologica, 70, 267-291.

TASSINARI, G., \& CAMPARA, D. (1996). Consequences of covert orient- 
ing to non-informative stimuli of different modalities: A unitary mechanism? Neuropsychologia, 34, 235-245.

Terry, K. M., Valdes, L. A., \& Neill, W. T. (1994). Does "inhibition of return" occur in discrimination tasks? Perception \& Psychophysics, 55, 279-286.

Thompson, G. C., \& Masterton, R. B. (1978). Brain stem auditory pathways involved in reflexive head orientation to sound. Journal of Neurophysiology, 41, 1183-1202.

VAUGHAN, J. (1984). Saccades directed at previously attended locations in space. In A. J. Gale \& C. W. Johnson (Eds.), Theoretical and applied aspects of eye movement research (pp. 143-150). Amsterdam: Elsevier, North-Holland.

WARD, L. M. (1994). Supramodal and modality-specific mechanisms for stimulus-driven shifts of auditory and visual attention. Canadian Journal of Experimental Psychology, 48, 242-259.

Whittington, D. A., Hepp-Reymond, M. C., \& Flood, W. (1981). Eye and head movements to auditory targets. Experimental Brain Research, 41, 358-363.

Woods, D. L., AlHo, K., \& AlgazI, A. (1992). Intermodal selective attention 1: Effects on event-related potentials to lateralized auditory and visual stimuli. Electroencephalography \& Clinical Neurophysiology, 82, 341-355.

WRIGHT, R. D., \& RICHARD, C. (1993, November). Inhibition-of-return of visual attention to multiple location cues. Paper presented at the annual meeting of the Psychonomic Society, Washington, DC.

WRIGHT, R. D., \& RICHARD, C. (1994). Inhibition-of-return at multiple locations following simultaneous and sequential location cues. Paper presented at the annual meeting of the Psychonomic Society, St. Louis.
WRIGHT, R. D., \& RICHARD, C. M. (in press). Inhibition of return is not reflexive. In R. D. Wright (Ed.), Visual attention. New York: Oxford University Press.

WurTz, R. H., \& Albano, J. E. (1980). Visual-motor function of primate superior colliculus. Annual Review of Neuroscience, 3, 189. 226.

Wurtz, R. H., Richmond, B. J., \& Judge, S. J. (1980). Vision during saccadic eye movements. III. Visual interactions in monkey superior colliculus. Journal of Neurophysiology, 43, 1168-1181.

WYNN, V. T. (1977). Simple reaction time-Evidence for two auditory pathways to the brain. Journal of Auditory Research, 17, 175-181.

\section{NOTES}

1. This between-participants factor was included in Experiment $1 \mathrm{~B}$ to ensure that any differences between cue-target and target-target inhibitory effects, such as those we had observed in Experiment $1 \mathrm{~A}$, could not be attributed to the physical characteristics of the stimuli themselves. Preliminary analysis of the results for Experiment 1B revealed that the between-participants factor of which sound served as cue and which served as target had no significant influence on performance, so it is not considered further.

2. The increase in the percentage of incorrect responses in Experiment IB is presumably attributable to participants' being given a much smaller time window in which to respond.

(Manuscript received May 6, 1996; revision accepted for publication January $29,1997$. ) 